\title{
Adaptation of a Cognitive-Behavioral Protocol for Generalized Anxiety Disorder Patients with Low Educational Attainment
}

\author{
Fernanda Correa Coutinho ${ }^{1}$ \\ Laboratory of Panic and Respiration, Institute of Psychiatry, Universidade Federal \\ do Rio de Janeiro, Rio de Janeiro, RJ, Brazil \\ National Institute for Translational Medicine, Rio de Janeiro, RJ, Brazil \\ Gisele Pereira Dias \\ Laboratory of Panic and Respiration, Institute of Psychiatry, Universidade Federal \\ do Rio de Janeiro, Rio de Janeiro, RJ, Brazil \\ Roberta Sá Fortes Marques \\ Hospital Universitário Clementino Fraga Filho, Universidade Federal do Rio de Janeiro, \\ Rio de Janeiro, RJ, Brazil \\ Bernard Pimentel Rangé \\ Institute of Psychology, Universidade Federal do Rio de Janeiro, Rio de Janeiro, RJ, Brazil \\ Marco Antonio Alves Brasil \\ Antonio Filpi \\ Medical School, Universidade Federal do Rio de Janeiro, Rio de Janeiro, RJ, Brazil \\ Antonio Egidio Nardi \\ Laboratory of Panic and Respiration, Institute of Psychiatry, Universidade Federal \\ do Rio de Janeiro, Rio de Janeiro, RJ, Brazil \\ National Institute for Translational Medicine, Rio de Janeiro, RJ, Brazil
}

\begin{abstract}
This article reports the experience of treating low-income patients with a primary diagnosis of generalized anxiety disorder (GAD) in a public hospital in Rio de Janeiro, Brazil. At the start of the project for outpatient treatment, which included the application of a cognitive model for GAD treatment, we observed that the majority of patients presented low educational level, which made it hard for them to understand key aspects of the cognitive-behavioral based treatment offered. Therefore, important adaptations to the treatment protocol were made necessary, including the way techniques were presented and applied, the therapeutic approach used, and even the duration of sessions. Since variations of cognitive therapy are increasingly being applied in hospital outpatient clinics in countries worldwide, the objective of this article is to present the adaptations performed and promote a discussion on the possible solutions for the difficulties faced in applying clinical psychology practice among patients with low educational and socioeconomic levels. This is a clinical study presenting an illustrative case, where adaptations to the treatment protocol were essential for the positive outcome of the case. It is concluded that, with the
\end{abstract}

Mailing address: Avenida Ataulfo de Paiva, 1079, sala 509, Leblon, Rio de Janeiro, RJ, Brazil. Phone: +55 21 22494789. E-mail: f.correacoutinho@gmail.com

This study was developed in partnership with the Institute of Psychiatry (IPUB) and the Clementino Fraga Filho University Hospital (HUCFF), associated with Rio de Janeiro Federal University (UFRJ) and received funding from the Research Foundation of the State of Rio de Janeiro (FAPERJ) and the National Council for Scientific and Technological Development (CNPq). 
scope of treatment in mind, the therapist must be attentive to the client's demands and particularities in order to achieve therapeutic success.

Keywords: Generalized anxiety disorder, cognitive-behavioral therapy, low-educational/ low-income patients, case report.

\section{Adaptação de um Protocolo Cognitivo Comportamental para Pacientes com Transtorno de Ansiedade Generalizada com Baixo Nível Educacional}

\section{Resumo}

Este artigo relata a experiência de tratamento de pacientes de baixa renda com diagnóstico primário de transtorno de ansiedade generalizada (TAG) em hospital público no Rio de Janeiro, Brasil. A ideia inicial do projeto era tratamento ambulatorial, com aplicação de um modelo cognitivo para o tratamento de TAG; porém, observamos que a maioria dos pacientes apresentou baixo nível educacional, o que tornava difícil sua compreensão dos principais aspectos do tratamento cognitivo-comportamental oferecido. Assim, foram feitas adaptações no protocolo de tratamento, incluindo a forma como as técnicas foram apresentadas e aplicadas, a abordagem terapêutica utilizada e a duração das sessões. Considerando que variações de terapias cognitivas são cada vez mais aplicadas em ambulatórios hospitalares em todo o mundo, o objetivo deste artigo é apresentar as adaptações realizadas e discutir possíveis soluções para as dificuldades enfrentadas na prática clínica com pacientes com baixo nível educacional e socioeconômico. Trata-se de um estudo clínico, com apresentação de um caso ilustrativo. Os resultados obtidos foram positivos e mostraram que as adaptações no protocolo foram essenciais para o sucesso terapêutico. Conclui-se que, tendo em mente o escopo do tratamento, o terapeuta deve estar atento às demandas e particularidades do cliente a fim de obter sucesso terapêutico.

Palavras-chave: Transtorno de ansiedade generalizada, terapia cognitivo-comportamental, baixo nível educacional/econômico, relato de caso.

\section{Adaptación de un Protocolo Cognitivo-Conductual de Trastornos de Ansiedad Generalizada para Pacientes con Bajo Nivel Educativo}

\section{Resumen}

Este artículo reporta la experiencia del tratamiento de pacientes de bajos recursos con diagnóstico primario de Trastorno de Ansiedad Generalizada (TAG) en hospitales públicos de Rio de Janeiro, Brasil. La idea original era el tratamiento ambulatorio con aplicación de un modelo cognitivo para el TAG. No obstante, el bajo nivel educativo presentado por la mayoría de los pacientes hace que les resulte difícil la comprensión de los principales aspectos del tratamiento cognitivo-conductual ofrecido. Adaptaciones fueron entonces realizadas en el protocolo de tratamiento, incluyendo cómo las técnicas fueron introducidas y aplicadas, el enfoque terapéutico utilizado y la duración de las sesiones. Dado que variantes de la terapia cognitiva son cada vez más aplicadas en la atención ambulatoria hospitalaria de todo el mundo, el objetivo de este artículo es presentar las adaptaciones realizadas y analizar posibles soluciones a las dificultades encontradas en la práctica de la psicología clínica con pacientes con bajo nivel educativo y socioeconómico, a partir de un caso ilustrativo. Los resultados obtenidos, positivos, indican que las adaptaciones realizadas fueron fundamentales para el éxito de la terapia. Podemos concluir que el terapeuta debe estar atento a las demandas y particularidad del cliente a fin de que la terapia sea exitosa.

Palabras clave: Trastorno de Ansiedad Generalizada, terapia cognitivo-conductual, bajo nivel educativo y socioeconómico, estudio de caso. 
The main characteristics of generalized anxiety disorder $(\mathrm{GAD})$ are invasive, uncontrollable and excessive worry and related somatic symptoms (American Psychiatric Association [APA], 2013). It is a chronic and incapacitating condition, common in many medical scenarios, that causes significant clinical suffering and impairs important aspects of the patients' lives. This impairment is associated with both social and occupational aspects, and degrades the overall quality of life. Various studies (Henning, Turk, Mennin, Fresco, \& Heimberg, 2007; Hoffmam, Dukes, \& Wittchen, 2008) have indicated that individuals with GAD have diminished social and work relations, and that the situation is aggravated by the presence of comorbidity, so that the disorder is considered a significant economic burden to society (Clark \& Beck, 2010).

It is a highly prevalent condition, and after treatment only about half of the patients manage to function at their best (Holaway, Rodebaugh, \& Heimberg, 2006). Moreover, the relapse rates are high, reaching 50\% (Hayes, Orsillo, $\&$ Roemer, 2010). Therefore, the search for improvements in treatment methods for GAD are frequently discussed among mental health professionals. The most common and empirically supported treatment methods for this condition include cognitive and behavioral therapies and their derivations (Hanrahan, Field, Jones, \& Davey, 2013).

In general, clinical treatment focuses on chronic and severe worry and associated anxiety (Coutinho, 2011). Besides this, attention is paid to maladaptive schemas related to general foreboding (including beliefs about the probability and consequences of threats to physical and psychological safety), personal vulnerability (including beliefs about inadequacy and lack of outside support and personal resources to deal with anxiety-producing situations), intolerance of uncertainty (including beliefs about the frequency, consequences, avoidance and non-acceptance of uncertain or ambiguous negative events) and metacognitive worry (including beliefs about the positive and negative effects of worry and their control; Clark \& Beck, 2010).

Dugas and collaborators (e.g., Dugas \& Koerner, 2005) developed a cognitive model for GAD in which intolerance of uncertainty (IU) a characteristic that results in a set of negative beliefs about uncertainty and their implications - is a central component (Dugas \& Robichaud, 2007). In the clinical practice, the treatment protocol suggested by Dugas and Robichaud (2007) is divided into six modules (Table 1).

Table 1

CBT-ITU Protocol (Robichaud, 2013)

\begin{tabular}{cl}
\hline Modules & \multicolumn{1}{c}{ Treatment modules include } \\
\hline 1 & Psychoeducation and worry awareness training \\
2 & Uncertainty recognition and exposure \\
3 & Reevaluating positive beliefs about the funtion of worry \\
4 & Problem reorrientation and training \\
5 & Cognitive exposure \\
6 & Relapse prevention \\
\hline
\end{tabular}

Note. CBT- IU Protocol = Cognitive Behavior Therapy - Intolerance of Uncertainty protocol.

The first treatment module includes psychoeducation of CBT and of the disorder. The idea is to ensure that clients understand the basis of the sessions and, thus, develop realistic expectations of treatment. The second module targets
IU. In this module, patients learn to understand the relationship between IU and excessive worry. They are instructed to recognize that situations of uncertainty are usually unavoidable and they are encouraged to experience them (Dugas 
\& Robichaud, 2007). The following module includes questioning and reassessment of positive beliefs about the benefits of worrying. A unique element of this treatment is that clients are taught to separate their concern into two categories: those which are capable of solving problems and those which are not. Thus, in the fourth module they work with solvable problems from the problem-solving technique. The fifth module focuses on the hypothetical problem, which is very common in patients with GAD. The technique used for these cases is imaginal exposure. Finally, the sixth module of treatment gives priority to preserving the gains achieved and preventing relapse (Dugas \& Robichaud, 2007).

The intolerance of uncertainty model (IUM), along with the model by Borkovec and colleagues (Covin, Ouimet, Seeds, \& Dozois, 2008 ) is among the two most empirically tested models for GAD. Several empirical investigations in the last decade have indicated the strong relationship between GAD and IU (Treanor, Erisman, Salters-Pedneault, Roemer, \& Orsillo, 2011), and they show that the clients gains in quality of life are associated with an increased ability to cope with the uncertainties of life and the ability to distinguish and solve problems as a result of this treatment model (Dugas et al., 2003; Ladouceur et al., 2000).

Randomized controlled trials evaluated treatment based on IUM for GAD in both individual formats (Dugas \& Robichaud, 2007; Gosselin, Ladouceur, Morin, Dugas, \& Baillargeon, 2006; Ladouceur et al., 2000), as well as in groups (Dugas et al., 2003), with results supporting the clinical effectiveness of both forms of treatment when compared with waiting lists and control conditions (Dugas et al., 2003; Dugas \& Robichaud, 2007; Ladouceur et al., 2000).

\section{The Challenges of Applying CBT in Low-Educational and Socioeconomic Populations}

A growing number of studies indicate the need for changes in treatment protocols, in order to increase adherence among patients in low and middle income countries (LMIC; Patel, Simon, Chowdhary, Kaaya, \& Araya, 2009). Other stud- ies, regardless of the country of origin, point to the fact that impoverished persons with anxiety disorders have demonstrated poor clinical outcomes (Mukherjee et al., 2006). Is it possible that independently of the country of origin, poor adherence is related to a higher prevalence of stress factors and psychosocial issues (Patel et al., 2009) that, along with other factors, directly influence the subject. A longitudinal study (Weich \& Lewis, 1998) in private households in England, Wales and Scotland, associated unemployment and poverty with the maintenance of episodes of depressive and anxious disorders, independently of occupational social class, and added that financial tensions were a strong predictor both of the beginning and of the maintenance of psychiatric condition, even when the standard of living was already set.

The cognitive model of anxiety considers that people who have a perception of themselves as being subject to internal or external risks about which there is poor control to provide sense of security as more susceptible to psychological disorders. It is also believed that vulnerability is related to a lasting tendency to misinterpret certain threatening or novel situations as dangerous (Clark \& Beck, 2010). It is therefore possible that people who go through financial difficulties and its consequences (e.g. living in risky areas) are more likely to be subjected to these triggering factors for the development or maintenance of an anxiety disorder.

Although a significant number of patients with GAD seek psychological treatment within the primary care centers, there is a large percentage of abandonment, besides the low therapeutic efficiency in post treatment assessments. Traditionally, there is a tendency to place on the patient the burden of responsibility for the adherence to any kind of treatment (Forman, 1993). However, adherence to treatment should be related, among other factors, to the therapeutic relationship (Mukherjee et al., 2006). In order to offer the best care possible, therapists need to make an effort with regard to understanding the decisions of patients on adherence in the context of their beliefs, attitudes and perceptions of welfare. In other words, the need for understanding 
the patients' context and adapting sessions and protocols accordingly is essential for therapeutic effectiveness in low income, vulnerable populations independent of their country of origin.

\section{The Context of our Study}

A treatment program using the IU protocol (e.g., Dugas \& Koerner, 2005) was started among patients with primary diagnosis of GAD at a public hospital associated with the Rio de Janeiro Federal University (UFRJ). A common characteristic of the patients in our sample was their low socioeconomic and schooling levels, which hampered the progress of the psychotherapeutic treatment. Since random clinical trials among patients suffering from GAD present high relapse rates, at the start of the work with these patients a hypothesis was raised that the treatment might have poor effectiveness, especially due to potentially high dropout rates. Considering the characteristics of the population participating in our study, we hypothesized that adjusting the protocol to the reality of our patients would be pivotal for enhancing the likelihood of success of the psychological service offered.

There is consensus about the importance of random clinical trials to demonstrate the effectiveness of treatment protocols, but it is also important to remember that most reports of these trials do not illustrate daily responses to protocols among patients with psychological problems, such as the difficulties and challenges faced by therapists when delivering cognitive-behavioral therapy (CBT) sessions. For patients with primary diagnosis of GAD from low-income communities, there is a need to adapt the information conveyed to them, so that they can more effectively benefit from the therapeutic work and so that CBT can be an instrument accessible to all.

As is happening in many other parts of the world, the use of CBT is growing in Brazil. The present study, of a clinical case treated in a university-based Brazilian hospital, illustrates some modifications that were made necessary not only for treating the particular case discussed, but also for several other low-educational/low-income patients during the four years of the clini- cal study undertaken with GAD patients by our group. This case report may lead to a re-evaluation of the way psychology caregivers carry out their outpatient clinical practice with anxious patients in public hospitals among low-schooling and socioeconomic populations worldwide.

\section{Method}

This case study had its assessment before (baseline), immediately after, thirty and sixty days after treatment for follow up.

\section{Assessment}

As with all patients sent by the psychiatry service, Mrs. M. was initially asked to answer the Mini-International Neuropsychiatric Interview (MINI.), which is considered the most appropriate tool to diagnose GAD as defined by the $4^{\text {th }}$ edition of the Diagnostic and Statistical Manual of Mental Disorders (DSM-IV; Sheehan et al., 1998), and by which the diagnoses of GAD was confirmed. Since the criteria for participating in the study was met, the patient was invited to take part in a treatment protocol based on the IU cognitive model. Patients were treated individually and received 19 sessions of 50 minutes each. After explaining the program and its aims, the patient signed the consent form.

In the next session, Mrs. M. filled the self report questionnaires that included measures of anxiety, worry, and depression and the measures were administered again after the treatment ended (19 sessions) and at 1- and 6 months follow up. Individual measures are described below.

\section{Self-Reported Outcome Measures}

- Beck Anxiety Inventory (BAI; Beck, Epstein, Brown, \& Steer, 1988), which is a 21item measure that assesses anxiety, with a focus on somatic symptoms;

- Beck Depression Inventory (BDI; Beck, Steer, \& Brown, 1996), a 21-item self-report scale that assesses the severity of affective, cognitive, motivational, vegetative, and psychomotor components of depression, widely used in treatment outcome studies of anxiety; 
- Penn State Worry Questionnaire (PSWQ; Meyer, Miller, Metzger, \& Borkovec, 1990), a 16-item measure of intensity of worry that has good psychometric properties and is widely used in research to measure pathological worry and change with treatment; and

- Intolerance of Uncertainty Scale (IUS; Freeston, Rhéaume, Letarte, \& Dugas, 1994), a 27-item self-report measure assessing cognitive, behavioral, and emotional responses to uncertainty in everyday life.

Mrs. M. showed a score of 9 in the BDI, 12 in the BAI, 53 in the PSWQ and 71 in the IUS, indicating minimal depression (BDI), low anxiety (BAI), high worry (PSWQ) and difficulty to dealing with the behavioral implication of uncertain situations (IUS).

Before session 1 (that is, before the application of the IU protocol itself started), the therapist met the patient to better understand the role of worry and anxiety in her life, to evaluate the contextual factors that could affect the symptoms and course of the therapy (for example, financial or family matters), and to also briefly explore the use of medication and history of previous therapies.

After analysis of her case history and application of the MINI questionnaire, which confirmed the diagnosis of GAD without comorbidities, her treatment started with the IU protocol (Dugas \& Robichaud, 2007).

\section{Case Introduction}

Mrs. M., a 65 year-old married white woman, did not complete primary school. She identified herself as a strong Christian. She lived with her husband, two daughters and a granddaughter in a low-income community in the city of Rio de Janeiro, Brazil, and had been under psychiatric care in our university-based, public hospital since 2008. Among its services, the hospital offers outpatient psychiatric and psychological treatment. Mrs. M. had been regularly taking alprazolam and citalopram. In 2013, she was referred by the attending psychiatrist to the psychological service for CBT treatment. At the time she arrived to the psychological service, Mrs. M. had been initially diagnosed with depressive disorder and was suspected of comorbid GAD. Mrs. M. was then sent to psychological assessment by the person in charge of the clinical study with patients with primary diagnosis of GAD. The area in Rio de Janeiro where Mrs. M. lives is known for its high rates of urban violence, including recurrent smuggling and gunfire.

Mrs. M. came to the psychology service sent by her psychiatrist for the treatment of anxiety symptoms that largely increased since the latest gunfire that took place near her home. In the initial interview, Ms. M. reported that her negative thoughts were constantly related to her fears and that she felt spiritless for anything else. She spent hours thinking of the violence in her city and of all hypothetical situations that could happen to her daughters and granddaughter. She reported that it significantly worsened when her daughter got a new job, because she felt very concerned about her daughter's physical integrity when getting back home late in the evening. Another great reason for anguish was her only granddaughter's future. Besides the fear of her getting sick, Mrs. M. was afraid she would not live long enough to help her with whatever she might need. When questioned, Mrs. M. reported she believed that all those concerns were valid, as they showed her love for her family.

Mrs. M. also reported symptoms of depression, including depressed mood, loss of interest, difficulty in starting tasks, fatigue, early insomnia, concentration difficulties, anxiety, social isolation, feelings of hopelessness, helplessness and worthlessness, which generated a strong feeling of guilty for thinking that the meaning of all that was that she doubted God.

Mrs. M. is the third daughter of a family of five siblings, with 2 older sisters and two younger brothers. She reported that she had never felt affection from her parents, that neither of them talked to their children and that they would never show their feelings. She reported a history of alcoholism in her father's family and mood disorders in her mother's. Her father used to drink very much when he was young, but since he got married, he quit or at least Mrs. M. did not remember him being drunk. He died of emphyse- 
ma, and from that point onwards, her mother acquired deep depression, but Mrs. M. only knew about her mother's diagnosis after her death. She reported that she constantly heard her mother say she wanted to die because she had already completed her trajectory on earth, and Mrs. M. also remembered she used to spend the day sleeping and that she hardly ever spoke or ate. One day she took her mother to the hospital because she had stopped eating. She was hospitalized and died days later.

She began working when she was 14 years old teaching children at home and when she was 15 , she was invited to teach at the school where she studied. At that time, she stopped studying and started working as a teacher, which lasted for three years. After that, she was an administrative assistant in a firm where she stayed for 13 years. When she got married, she stopped working and was supported by her husband, who worked as an independent car painter.

She looked for neurological treatment 10 years ago because of a strong and constant headache and when she reported that she felt 'something strange that came from the heart and went to the mouth', the doctor said it was anxiety and she remembered doctors telling her mother she had the same diagnosis. She was advised by a neurologist to see a psychiatrist and she has kept stable by medication for five years. She even had some group therapy, but said she did not like it, as she was not willing to talk about her personal life to strangers. Although she did not like it much, she remained under treatment until her daughter had problems during pregnancy and needed her support.

Mrs. M. reported she accepted taking part in the treatment because it was individual and because she knew that she needed help to control her worries. She reported that even her daughters complained that she was too worried and that it suffocated them. She also reported her family relationship was very good, despite their complaints about this feeling of suffocation and that she knew she was not happy because she did not have enough time for her family, since she spent the day thinking and trying to control possible negative events.

\section{Case Conceptualization}

The conceptualization of the case followed the traditional model of Aaron Beck's CBT, in which personal experiences, influenced by parents and society, result in three levels of cognition, and shape personality together with biological and environmental factors (Figure 1). Her parents had always been very closed and she did not remember having family dialogue. She reported she learned early on to be reserved and to not expose her feelings. She said her mother used to say that the world was very dangerous, that at any moment something bad could happen and that Mrs. M. would be responsible if she were not able to predict what was coming. Mrs. M. had a maternal family history of mental illness, which may have predisposed her to psychopathology for biological and/or environmental reasons. Her mother was always very anxious and she developed severe depression after her husband's death.

Mrs. M. came from a family in which 'a woman's life should revolve around caring for the children while her husband worked.' The belief that women were the weaker sex and that she should protect her children at any cost led her to leave her job as soon as she got married and to become solely responsible for taking care of the home. Thus, Mrs. M. reported that her anxiety rose to a clinically significant level after marriage, for 'building and maintaining a family required great care and dedication'. For her, worry was synonymous with affection and dedication, which contributed to the maintenance of the disorder. As she could not control the violence of the big city, she started spending hours of her day with hypothetical thoughts of "what if' something bad happens to one of my daughters or granddaughter, and as she did not learn skillful ways of dealing with these emotions, she used to pray as a way of distracting herself, but at that time it 'no longer worked as before'. The meaning of worry as affection conflicted with the guilt for not trusting God as she should and for keeping her thoughts on potential tragedy, all of which made her accept initiating therapy.

When she came to therapy, besides feeling guilty, Mrs. M. had already been in this cycle of 


\begin{tabular}{|c|c|c|}
\hline \multicolumn{3}{|c|}{$\begin{array}{l}\text { Relevant Childhood Data } \\
\text { Anxious and severe depression mother } \\
\text { No dialogue with parents }\end{array}$} \\
\hline \multicolumn{3}{|c|}{$\begin{array}{l}\text { Core Belief(s) } \\
\text { I am vulnerable } \\
\text { I am weak }\end{array}$} \\
\hline \multicolumn{3}{|c|}{$\begin{array}{l}\text { Conditional Assumptions / Attitudes / Rules } \\
\text { World was too dangerous } \\
\text { Women were the weaker sex } \\
\text { If I care and protect my family, I am strong } \\
\text { If I do not protect my family, I'm weak }\end{array}$} \\
\hline \multicolumn{3}{|c|}{$\begin{array}{l}\text { Compensatory/Coping Strategy(ies) } \\
\text { Suppression of thoughts } \\
\text { Try to find comfort in religion } \\
\text { Pray more than usual }\end{array}$} \\
\hline $\begin{array}{c}\text { Situation } 1 \\
\text { My daughter told me about her } \\
\text { new job }\end{array}$ & $\begin{array}{c}\text { Situation 1 } \\
\text { The doctor said my } \\
\text { grandaughter has sore throat }\end{array}$ & $\begin{array}{c}\text { Situation } 1 \\
\text { I saw a police car in my street }\end{array}$ \\
\hline $\begin{array}{l}\text { Automatic Thought } \\
\text { It is very dangerous for her } \\
\text { to come back home alone! } \\
\text { She can be robbed, raped, etc }\end{array}$ & $\begin{array}{l}\text { Automatic Thought } \\
\text { The doctor is not looking right. } \\
\text { It must be something more } \\
\text { serious. } \\
\text { It will get worse and when it } \\
\text { does, it will be too late }\end{array}$ & $\begin{array}{l}\text { Automatic Thought } \\
\text { A misfortune happened with } \\
\text { someone. } \\
\text { Help! I am sure it is in my } \\
\text { house }\end{array}$ \\
\hline $\begin{array}{l}\text { Meaning of Automatic Thoug } \\
\text { ht }\end{array}$ & $\begin{array}{c}\text { Meaning of } \\
\text { Automatic Thought } \\
\text { I am weak }\end{array}$ & $\begin{array}{l}\text { Meaning of } \\
\text { Automatic Thought } \\
\text { I am vulnerable }\end{array}$ \\
\hline $\begin{array}{l}\text { Emotion } \\
\text { Anxiety }\end{array}$ & $\begin{array}{l}\text { Emotion } \\
\text { Affliction }\end{array}$ & $\begin{array}{c}\text { Emotion } \\
\text { Fear and anxiety }\end{array}$ \\
\hline $\begin{array}{l}\text { Behavior } \\
\text { I called my daughter many } \\
\text { times. When she was about to } \\
\text { arrive home I went out to meet } \\
\text { her and come home together }\end{array}$ & $\begin{array}{l}\text { Behavior } \\
\text { I checked if my granddaughter } \\
\text { had a fever all the time. I } \\
\text { called the pediatrician and read } \\
\text { about diseases on the internet }\end{array}$ & $\begin{array}{c}\text { Behavior } \\
\text { I cried and ran home }\end{array}$ \\
\hline
\end{tabular}

Figure 1. Mrs. M's Cogntive Conceptualization Diagram. Adapted from Cognitive behavior therapy worksheet packet. Copyright 2011 by Judith S. Beck. Bala Cynwyd, PA: Beck Institute for Cognitive Behavior Therapy. 
anxiety and prayer for 30 years, and she could no longer do any other activity in her daily life. This reinforced her belief in her vulnerability in dealing with uncertain situations, which in turn increased her chronic feeling of unhappiness.

\section{Course of Treatment and Assessment of Progress}

The first theme covered was psychoeducation and awareness of worries. These first sessions went more slowly due to Mrs. M.'s difficulty to assimilate the concepts of the therapy. This difficulty had already been demonstrated when filling out the self-report questionnaires prior to the treatment. Despite these difficulties, she worked hard and performed all the activities proposed as homework, enabling her to overcome the initial obstacles and benefit from the therapy. A recurring difficulty was the understanding and differentiation of "thought", "feeling" and "behavior". The task was given several times and required flexibility of the therapist regarding the dynamics of the sessions. A common error was for Mrs. M. to bring as an example of thinking "I was nervous, anxious". An important point during all the modules was the modification/adjustment of the terms used in CBT, such as cognition, cognitive distortion and IU, which were replaced, respectively, by thinking, thinking errors and "I can't stand doubts". Another example, also in the first module, was the categorization of the situations triggering worry and anxiety. Dugas and Robichaud (2007) suggest real and hypothetical situations, but the patient preferred to name them "true situations" and "invented situations". In this case, it was fundamental for the therapist to adjust to the way the patient referred to the concepts covered, to assure her understanding regardless of the change in terminology.

The first treatment module lasted longer for this patient because it was essential for her to become familiar with the concepts of the therapy. Only after the fourth session was it possible to start module 2 of the protocol, which means the first module took twice as many sessions (4 instead of 2) when compared with the original protocol. In this module, the theme addressed was "recognition of uncertainty and behavioral exposure". At this stage, the therapist was faced with a particularity of the social context of low-educational/low-income patients: the high prevalence of violence and the lack of resources and support in these communities. An example of this was the proposed exercise in behavioral exposure, in which the patient should experience a situation in which she had to deal with feelings of uncertainty. Therefore, it was proposed that she would think of situations in which she felt anxious as a result of IU, so that we could work on her imaginary exposure. Most of the time this does not pose difficulties, but with Mrs. M. it was different. On being asked about situations in which she felt this way, she suggested: "I'm afraid and feel insecure when my daughter returns from work alone at night and passes through an abandoned street; I could go meet her and walk back with her, but I don't think I can manage it", and "I could go out to play with my granddaughter in the street near where I live, but there are lots of muggings there and I'm afraid". In these two situations it was not advisable to do the exposure exercise with the patient, because this could really have posed her real risks to her physical and psychological integrity. It was important to understand the patient's context and define what the real problem was, its solution or if it was a problem without solution. Sometimes in threatening situations, patients do not have more possibilities than he/she can see. Problem solving training was used for the problems that could be solved.

Modules 3 and 4 ("reassessment of the advantages or worry" and "training in problem solving") were more reassuring for the patient. It was not necessary to spend extra time on this, and the sessions became more dynamic. An interesting point is the association Mrs. M. made between worrying about someone and caring for someone. She reported various positive beliefs in worrying about people, mainly her daughters and granddaughter. Since she was a dedicated patient, she quickly became aware of her distortions and strived to correct them. The problem solving technique was a tool that she seized without much difficulty. In this case, as in any 
other related to homework, it was of fundamental importance for the therapist to focus on asking for feedback both during the sessions and at the end of each one, as well as on having an understanding attitude in relation to the patient's difficulties with the requested tasks. With this, Mrs. M. felt at ease to ask for clarification of her doubts and better absorbed the objective of the proposed exercises.

Module 5 was the moment of greatest difficultly in Mrs. M.'s treatment. Like in module 1 , the sessions had to be extended a bit and the patient faced a large obstacle. It is common for low-educational/low-income patients in Brazil to have a strong network of religious support, which can be a double-edged sword. In other words, while religion can be a protective factor, acting as an ally in the practice of health professionals, at times it can also pose a hindrance to the treatment progress. The patient was very involved in religious activities and this became an issue that hampered the achievement of this part of the protocol. Module 5 includes imaginary exposure, in which a scenario is created with great emotional weight and the exposure is performed until a reduction of the anxiety related to it is noted. That exercise conflicted with some of the patient's beliefs, such as "I can't think about this, because God won't like it. He'll think that I want this to happen"; "This is wrong, I can't think about bad things, I have to believe this won't happen, God won't allow it!" At this moment, the good rapport established between the therapist and patient enabled the conclusion of this task. It was a difficult situation that was very emotionally draining for the patient and she asked to end the session. Once again, the therapist's empathetic and understanding posture was fundamental. It took a session to discuss the client's thoughts in relation to that exposure and reassure the importance of that module for the treatment. The discussion of religious issues by Mrs. M with her church friends was another important point of treatment. Mrs. M. reported in therapy that friends who did not trust their therapists ended up not getting the desired improvement and giving up treatment. As a result of Socratic questioning and analysis of advantages and disadvantages, Mrs. M. decided to continue with the exercise suggested by the therapist. Mrs. M. accepted continuing for all the progress she had already made. At the end of this step, Mrs. M. told the therapist: "I lacked courage to do this activity, but since you said I could do it, I believed you and did it! I feel better for this!". In general, this technique is performed with the use of a recorder, because it is considered important to make use of other sensorial systems in the integration of stimuli for the generation of more adaptive responses. In this case, for the patient to hear his/her own voice reporting his/her fears. In this respect, another adaptation necessary was to replace the recorder with reading aloud, since the patient could not afford purchasing such a device.

Besides the changes in the number of sessions (Table 2), during the entire treatment period it was necessary for the therapist to be flexible, meaning maintaining an empathetic attitude, valuing the patient, adapting terminology, using many practical and concrete examples and being attentive to the patient's reality.

Table 2

Adaptation of the Number os Sessions

\begin{tabular}{ccc}
\hline Modules & $\begin{array}{c}\text { Sessions suggested by the literature } / \\
\text { adapted for the patient }\end{array}$ & Treatment modules include \\
\hline 1 & $1-2 / 1-4$ & $\begin{array}{c}\text { Psychoeducation and worry awareness training } \\
\text { Uncertainty recognition and exposure }\end{array}$ \\
2 & $3-6 / 5-8$ & $\begin{array}{c}\text { Reevaluating positive beliefs about the funtion of worry } \\
3\end{array}$ \\
4 & $9-8 / 9-10$ & Problem reorrientation and training \\
5 & $12-14 / 14-17$ & Cognitive exposure \\
6 & $15-16 / 18-19$ & Relapse prevention \\
\hline
\end{tabular}




\section{Results}

The pre-treatment, post-treatment and follow-up scores are provided in Table 3 . It is important to observe that unlike the report of significant improvement from the patient, the scores on most of the questionnaires indicate a worse condition just after treatment and one month afterward. Treatment improvement, however, was observed from both patient's report and standardized scales/questionnaires, as reflected in the six-month follow-up scores.

Table 3

Assement Measures at Baseline, Posttreatment, and Follow-Up Period

\begin{tabular}{ccccc}
\hline Measures & Baseline & Posttreatment & 1-month follow up & 6-months follow up \\
\hline PSWQ & 53 & 62 & 40 & 38 \\
BDI & 9 & 18 & 13 & 9 \\
BAI & 12 & 5 & 23 & 7 \\
IUS & 71 & 85 & 85 & 57 \\
\hline
\end{tabular}

In the first follow-up appointment, which took place one week after the last CBT session, the patient was left in the room and was encouraged to take her time filling out the questionnaires on her own. Before beginning, Mrs. M. was keen to find the psychologist who attended her and she reported feeling much better after treatment and that she was very grateful for all that had been done over the past months. However, it is interesting to note that, with the exception of BAI, all the other scores increased. BAI is a 21- multiple-choice question self-report inventory used for measuring the severity of anxiety in children and adults. The patient responds to a list of common symptoms of anxiety, such as feeling hot and wobbliness in legs. It is believed that there is no greater difficulty in answering this questionnaire.

The other evaluations require interpretation, although they are also multiple choice inventories. It is important to mention that the patient left the room saying she had difficulty answering the questionnaires alone and she revealed doubt understanding the questions.

In the following assessments (1- and 6-months follow-up) an independent appraiser was chosen (who had not had contact with the patient throughout the therapeutic process) to stay in the room and help when requested. Mrs. M. reported relief to know that she would have support and she used it almost all the time she was there. The results of the questionnaires were more appropriate to the clinical report. This suggests that although they are considered selfreport measures, the PSWQ, IUS and the BDI require a higher level of education from the respondent to do it on their own.

\section{Discussion}

GAD treatment in patients with low income and living in dangerous areas will possibly require longer and more arduous psychotherapy work for both psychologist and patient. GAD is defined as excessive and chronic worry and although the content of the concerns may vary, it tends to be large and pervasive and can include a range of areas, such as interpersonal relationships, physical health, finances, and global and/ or minor issues (such as care with the home or children; APA, 2013). A real lack of financial resources, living in potentially violent areas and the lack of knowledge may enhance the concerns and should be in the mind of the psychologist who will work with this potentially more vulnerable patient (Kim \& Cardemil, 2012). In fact, increasing the availability and quality of mental health services provided to persons from historically disadvantaged racial and ethnic groups is a necessity and many previous authors have in- 
dicated that traditional mental health treatments should be modified to match clients' cultural contexts (Griner \& Smith, 2006).

Some complicating factors for the application of a cognitive-behavioral protocol targeting IU (Robichaud, 2013) have made it necessary that adjustments occur during treatment. Behavioral exposure had to be adapted to the context in which she lived. One of her feared hypothesis was of being assaulted while playing with her granddaughter on the street next to her house, which caused her to never leave the house with her granddaughter. Knowing that this was a real and frequent possibility, the option was to explore other possibilities. Mrs. M. discovered a community space not as close as the previous one, but still within walking distance and she agreed to take her granddaughter there.

Another problematic factor was the time during sessions to prepare the greater amount of written material that Mrs. M. used to take home. Records have always been an extra difficulty and as a solution, the therapist had to use a much longer time explaining and filling in the forms during sessions with examples the client brought. These completed forms were filled either by the therapist or by Mrs. M. and she took them home and used them as examples to complete the tasks of the week. For a patient profile with low education, it is important to keep in mind the inevitability of the flexibility of time and the way to implement the techniques (being even more didactic and explanatory, taking care not to be patronizing). As for patients living in vulnerable areas, understanding their context and being aware of what risks or lack of resources there are, contributes to a better therapeutic relationship and consequently to treatment adherence (Kim \& Cardemil, 2012).

In Mrs. M.'s particular case, being already over 60 years old, she would not have to pay for the transport to get to therapy, even if not participating in the clinical trial. In cases in which participating patients were under 60 , however, a transportation allowance was offered. Nevertheless, not every patient that seeks healthcare becomes a volunteer in clinical studies, and therefore could be in a position of not being able to afford the transportation to receive weekly treatment. In the context of public health, drop-out of patients appears to be greater than in private practice, and a common mistake is to place the responsibility of treatment solely on the patient (Mukherjee et al., 2006). It is important to watch out for the signs the patient is displaying. It could be that their absence is due to a lack of money to pay for transportation toward the hospital/clinic, and that their delayed arrival to sessions could be due to problems with inefficient public transport. Treatment abandonment could also be related to the patient thinking he/she had failed to complete homework and for being ashamed of it he/ she missed some important point in the session. Or yet, he/she did not feel understood in relation to the context in which they live. The effort of the health professional to understand the complicating factors and provide the best treatment should include understanding clients' attitudes within the environment in which they live and the beliefs that move them.

Because it is part of a research study, therapy was funded by the Brazilian National Council for Scientific and Technological Development (CNPq), without which Mrs. M.'s treatment would not have been possible. In addition, the fact that the patient is senior assures gratuity on public transport, even if she was not taking part in our study and found treatment in another hospital offering psychological service. Mrs. M. quickly developed a rapport with her therapist and was open to providing ongoing feedback about the therapy and her progress.

Another important point with regard to treatment access was related to Mrs. M.'s pharmacological treatment, which started in 2008. At that time, she was constantly complaining and expecting something disastrous to happen to herself or her daughters. In the consultations, she also reported fear of being diagnosed with a terminal illness. As a consequence of these problems, she started to have anxiety attacks in which the main symptom was tachycardia. From the first consultation, the decision was made to medicate her with the diazepine drug alprazolam (two 1-mg tablets per day) and citalopram, an antidepressant drug of the selective serotonin reup- 
take inhibitor class (20 mg per day). This choice was based on the depressive character of the symptoms that are customarily associated with these situations (Shatzberg \& Nemeroff, 2009). In the case of the hospital in which the treatment took place, medicines are not delivered to the patients in the outpatient clinic. Instead, the patient must take the prescription to a pharmacy to obtain it. This is facilitated financially by the Popular Pharmacy program in the state of Rio de Janeiro, under which certain drugs are sold at heavily subsidized prices, along with the promotion by the federal government of generic drugs, which besides being off-patent are also given tax breaks, making them more accessible to poor people.

According to Kazantzis, Cronin, Dattilio, and Dobson (2013), knowledge, theories, techniques and strategies do not have any practical utility unless therapists are able to relate with their clients. A characteristic of Brazil's National Health System is the diversity of the patients, so before starting to use any particular technique it is necessary to understand where and how these patients are situated in society and what is their view of themselves and their surroundings. This, however, is not restricted to the Brazilian context but to any context - in both developed and developing countries - where cognitively demanding interventions are applied to populations with low educational status. In the CBT approach, psychoeducation is the first step in treating the psychological disturbance and must be introduced in the patient's context, including adapting to terms and expressions used by him or her.

After Mrs. M. underwent the initial assessment and was accepted for treatment, the therapist conducted a clinical interview where the focus was on listening and trying to understand her needs and demands. This interview was crucial to establish the therapeutic alliance. At first, the therapist assumed a posture of greater responsibility, to convey the feeling of security that the patient needed, and then gradually invited Mrs. $\mathrm{M}$. to become more participative and responsible for her own therapeutic process. The reality is that many low-income patients have precon- ceived notions regarding psychological treatment and are doubtful of therapy's utility. Consequently, for example, Levy and O'Hara (2010) important research has found that individuals from low-income backgrounds are less likely to seek formal mental health services. It is up to the therapist to show an attitude of confidence in the treatment.

As a clinical suggestion, based on analysis of all the patients treated in the program and illustrated herein with Mrs. M.'s case, we can highlight the importance of showing understanding of the situations faced by the patients by using their language and replacing standard psychological expressions with more vernacular ones (e.g., "hypothetical situation" with "invented" or "imagined" situation). Flexibility regarding the number and duration of sessions is also an important factor. Cardemil (2010) suggests that specific cultural groups (for example: Caucasians, African Americans, Latin Americans, and Asian Americans) need particular adaptations designed to enhance treatment acceptability and adherence.

Another important point is the homework tasks. In the case of Mrs. M., she was very dedicated, something that is common among this sample of the population. In general, they feel gratitude and appreciation for the therapist and also know the treatment has a predetermined duration, so they want to take maximum advantage of it. On the other hand, many patients feel insecure about making mistakes in their homework. It is important for the therapist to give various examples to make sure the patient understands the task before asking them to do it on their own. If the patient still does the task differently than what it has been requested, it is important to go over it again together. Throughout the process, though, a non-patronizing but compassionate attitude by the therapist is essential.

As mentioned, it is very common for lowincome people in Brazil to have a very strong religious support network, which can be a double-edged sword. While religion can be a protective factor and act as an ally to therapy, it can also pose an obstacle to the progress of treatment (Kersting, 2003). The focus patient 
here was closely involved with her church and this in some ways hindered the realization of the protocol as originally proposed, a hurdle only overcome with the help of a strong therapeutic alliance.

Regarding the results of the self-report questionnaires and their discrepancies with the patient's discourse, this also occurred with other subjects who were participating in the study. Analyzing the scores obtained in light of the number of years of schooling, we found that the fewer years of schooling, the greater the discrepancy of the results of the self-reported scores and the clinical evaluation of improvement. We raised several hypotheses, the main one being that the baseline questionnaires were filled in by the participants along with the therapist and the next ones were filled in by the patients on their own. Therefore, in the 6-month follow-up we opted to have a therapist explain the procedure again, including the Likert scale, commonly used in self-applied questionnaires. Besides this, the therapist also was available to clarify doubts. Using these resources, the scores attained after six months were better. This gives some support to the hypothesis that the questionnaires are generally hard to be fully understood by patients with low schooling levels, although this hypothesis should be specifically tested in order to be fully confirmed.

We believe that this case report enabled us to provide more details of the main questions that should be borne in mind by psychologists who work in the context of public health services. Besides, the case described was in many ways similar to that of other patients who seek treatment in public outpatient clinics allowing a careful degree of generalization not only for patients with GAD, but also for those with other psychological disturbances that are treated with cognitive-behavioral protocols.

The main points of convergence are initially to convey a feeling of security to patients that they will be heard and supported without any type of prejudgment, and that the therapist is there to help them feel better about themselves and improve their relationships and overall quality of life. The therapist must assume the initial responsibility for the treatment before sharing it with the patient. Soon thereafter, before the start of the protocol itself, care must be taken to understand the patients' context and allow them to express their questions and concerns when following the structure proposed by the protocol to be reproduced. The idea is to be flexible and understand the patients' context to enable the therapist to respond to them in ways that maximize the likelihood of a successful therapeutic outcome, considering that people with low-income are more likely to abandon treatment prematurely (Miranda, Azocar, Organista, Dwyer, \& Areane, 2003).

During the treatment it should be borne in mind that the structure of each session can be modified, and most importantly, to follow the needs of the patient as much as possible. It is common that, in the anxiety to apply a specific technique, the therapist becomes detached from the patient, after which the therapy's effectiveness will be seriously undermined. Time management during sessions is another essential skill for the psychotherapist working with loweducational populations. Finding a fine balance between keeping focus and track of the session and, at the same time, understanding that sessions with these patients might be longer in duration is a pivotal skill to increase the likelihood of treatment adherence and success. As proposed by Kim and Cardemil (2012) in the study of therapeutic efficacy for patients with low-income, clinical work for this population should include some consideration of adaptations to the structure of the therapy, aiming at increasing the acceptability and attractiveness of the intervention to low-income clients.

Finally, the practice of cognitive therapy is clearly relational (Beck, Rush, Shaw, \& Emery, 1979) and in the context of clinical work with disadvantaged populations this cannot be overlooked. Therefore, in general, a malleable session structure helps the therapist to work more effectively and contributes to a strong therapeutic alliance in a relationship of collaboration with the client. Although this work refers to patients with GAD, the considerations raised here can apply to other treatment protocols used with 
patients with various psychological disturbances inserted in the same context. The relevance of such an endeavor is confirmed by the American Psychological Association (APA, 2001), which has indicated the improvement of mental health treatment for ethnic minority and low income groups as a priority. Due to the relative lack of studies illustrating the need for adaptation of protocols in the clinical practice, more research is certainly necessary on the subject.

\section{References}

American Psychological Association. (2001). Mental health issues in TANF reauthorization. Retrieved from http://www.apa.org/pi/urban/tanfreg.html

American Psychiatric Association. (2013). Diagnostic and statistical manual of mental disorders ( $5^{\text {th }}$ ed.). Arlington, VA: Author.

Beck, J. S. (2011). Cognitive behavior therapy: Basics and beyond ( $2^{\text {nd }}$ ed.). New York: The Guilford Publications.

Beck, A. T., Epstein, N., Brown, G., \& Steer, R. A. (1988). An inventory for measuring clinical anxiety: Psychometric properties. Journal of Consulting and Clinical Psychology, 56(6), 893897. doi:10.1037/0022-006X.56.6.893

Beck, A. T., Rush, A. J., Shaw, B. F., \& Emery, G. (1979). Cognitive Therapy of Depression. New York: Guilford Press.

Beck, A. T., Steer, R. A., \& Brown, G. K. (1996). Beck Depression Inventory Manual (2 ${ }^{\text {nd }}$ ed.). San Antonio, TX, Psychological Corporation.

Cardemil, E. V. (2010). Cultural adaptations to empirically supported treatments: A research agenda. The Scientific Review of Mental Health Practice, 7, 8-21.

Clark, D. A., \& Beck, A. T. (2010). Cognitive Therapy of Anxiety Disorder: Science and practice. New York: The Guilford Publications.

Coutinho, F. C. (2011). Efetividade da abordagem cognitivo-comportamental em grupo para pacientes com transtorno de ansiedade generalizada: Um teste transcultural (Master's dissertation, Instituto de Psicologia, Universidade Federal do Rio de Janeiro, RJ, Brazil).

Covin, R., Ouimet, A. J., Seeds, P. M., \& Dozois, D. J. A. (2008). A meta-analysis of CBT for patho- logical worry among clients with GAD. Journal of Anxiety Disorders, 22(1), 108-116.

Dugas, M. J., \& Koerner, N. (2005). Cognitive-behavioral treatment for generalized anxiety disorder: Current status and future directions. Journal of Cognitive Psychotherapy, 19(1), 61-68. doi:10.1891/jcop.19.1.61.66326

Dugas, M. J., Ladouceur, R., Leger, E., Freeston, M. H., Langolis, F., Provencher, M. D., \& Boisvert, J.-M. (2003). Group cognitive-behavioral therapy for generalized anxiety disorder: Treatment outcome and long-term follow-up. Journal of Consulting and Clinical Psychology, 71(4), 821-825. doi:10.1037/0022-

Dugas, M. J., \& Robichaud, M. (2007). CognitiveBehavioral Treatment for Generalized Anxiety Disorder: From science to practice. New York: Routledge.

Forman, L. (1993). Medication: Reasons and interventions for noncompliance. Journal of Psychosocial Nursing and Mental Health Services, 31(10), 23-25.

Freeston, M. H., Rhéaume, J., Letarte, H., \& Dugas M. J. (1994). Why do people worry? Personality and Individual Differences, 17(6), 791-802. doi:10.1016/0191-8869(94)90048-5

Gosselin, P., Ladouceur, R., Morin, C. M., Dugas, M. J., \& Baillargeon, L. (2006). Benzodiazepine discontinuation among adults with GAD: A randomized trial of cognitive-behavioral therapy. Journal of Consulting and Clinical Psychology, 74(5), 908-919. doi:10.1037/0022006X.74.5.908

Griner, D., \& Smith, T. B. (2006). Culturally adapted mental health intervention: A metaanalytic review. Psychotherapy: Theory, Research, Practice, Training, 43(4), 531-548. doi:10.1037/0033-3204.43.4.531

Hanrahan, F., Field, A. P., Jones, F. W., \& Davey, G. C. L. (2013). A meta-analysis of cognitive therapy for worry in generalized anxiety disorder. Clinical Psychology Review, 33(1), 120-132. doi:10.1016/j.cpr.2012.10.008

Hayes, S., A., Orsillo, S. M., \& Roemer, L. (2010). Changes in proposed mechanisms of action during an acceptance-based behavior therapy for generalized anxiety disorder. Behaviour Research and Therapy, 48(3), 238-245. doi:10.1002/da.20249 
Henning, E. R., Turk, C. L., Mennin, D. S., Fresco, D. M., \& Heimberg, R. G. (2007). Impairment and quality of life in individuals with generalized anxiety disorder. Depression and Anxiety, 24(5), 342-349. doi:10.1002/da.20249

Hoffmam, D. L., Dukes, E. M., \& Wittchen, H. U. (2008). Human and economic burden of generalized anxiety disorder. Depression and Anxiety, 25(1), 72-90. doi:10.1002/da.20257

Holaway, R. M., Rodebaugh, T. L., \& Heimberg, R. G. (2006). The epidemiology of worry and generalized anxiety disorder. In G. Davey \& A. Wells (Eds.), Worry and its Psychological Disorders: Theory, assessment and treatment (pp. 3-19). Chichester, UK: John Wiley \& Sons.

Kazantzis, N., Cronin, T. J., Dattilio, F. M., \& Dobson, K. S. (2013). Introduction: Using techniques via the therapeutic relationship. Cognitive and Behavioral Practice, 20(4), 385389. doi:10.1016/j.cbpra.2013.03.005

Kersting, K. (2003). Religion and spirituality in the treatment room. American Psychological Association, 34(11), 40. Retrieved from http://www. apa.org/monitor/dec03/religion.aspx

Kim, S., \& Cardemil, E. (2012). Effective psychotherapy with low-income clients: The importance of attending to social class. Journal of Contemporary Psychotherapy, 42(1), 27-35. doi:10.1007/ s10879-011-9194-0

Ladouceur, R., Dugas, M. J., Freeston, M. H., Léger, E., Gagnon, F, \& Thibodeau, N. (2000). Efficacy of a cognitive-behavioral treatment for generalized anxiety disorder: Evaluation in a controlled clinical trial. Journal of Consulting and Clinical Psychology, 68(6), 957-964. doi:10.1037/0022006X.68.6.957

Levy, L. B., \& O’Hara, M. W. (2010). Psychotherapeutic interventions for depressed, low-income women: A review of the literature. Clinical Psychology Review, 30, 934-950. doi:10.1016/j. cpr.2010.06.006

Miranda, J., Azocar, F., Organista, K. C., Dwyer, E., \& Areane, P. (2003). Treatment of depression among impoverished primary care patients from ethnic minority groups. Psychiatric Services, 54(2), 219-225. doi:10.1176/appi.ps.54.2.219
Meyer, T. J., Miller, M. L., Metzger, R. L., \& Borkovec, T. D. (1990). Development and validation of the Penn State Worry Questionnaire. Behaviour Research and Therapy, 28(6), 487-496. doi:10.1016/0005-7967(90)90135-6

Mukherjee, S., Sullivan, G., Perry, D., Verdugo, B., Means-Christensen, A., Schraufnagel, T., \& Roy-Byrne, P. P. (2006). Adherence to treatment among economically disadvantaged patients with panic disorder. Psychiatric Services, 57(12), 1745-1750

Patel, V., Simon, G., Chowdhary, N., Kaaya, S., \& Araya, R. (2009). Packages of care for depression in Low- and Middle-Income Countries. PLoS Medicine, 6(10), e1000159. doi:10.1371/journal.pmed.1000159

Robichaud, M. (2013). Cognitive behavior therapy targeting intolerance of uncertainty: Application to a clinical case of generalized anxiety disorder. Cognitive and Behavioral Practice, 20(3), 251263. doi:10.1016/j.cbpra.2012.09.001

Shatzberg, A. F., \& Nemeroff, C. B. (2009) Textbook of Psychopharmacology (4 $4^{\text {th }}$ ed.). Schatzberg, German: The American Psychiatric Publishing.

Sheehan, D. V., Lecrubier, Y., Sheehan, K. H., Amorim, P., Janavs, J., Weiller, E., \& Dunbar, G. C. (1998). The Mini-International Neuropsychiatric Interview (M.I.N.I.): The development and validation of a structured diagnostic psychiatric interview for DSM-IV and ICD-10. Journal of Clinical Psychiatry, 59(20), 22-33.

Treanor, M., Erisman, S. M., Salters-Pedneault, K., Roemer, L., \& Orsillo, S. M. (2011). Acceptance-based behavioral therapy for GAD: Effects on outcomes from three theoretical models. Depression and Anxiety, 28(2), 127-136. doi:10.1002/da.20766

Weich, S., \& Lewis, G. (1998). Poverty, unemployment, and common mental disorders: Population based cohort study. BMJ : British Medical Journal, 317(7151), 115-119. doi:10.1136/ bmj.317.7151.115

Recebido: 16/06/2016

$1^{a}$ revisão: 07/12/2016

Aceite final: 13/12/2016 